\title{
Retratos de experiencias: formas de narrar la vida en Las fotos y "iQue tengan buen viaje!» de Inés Ulanovsky ${ }^{1}$
}

\author{
María Eugenia Argañaraz \\ Doctora en Letras \\ CIS-IDES-CONICET \\ https://orcid.org/0000-0002-7645-7395 \\ eugearga@gmail.com
}

\begin{abstract}
Resumen
Analizo el último libro de Inés Ulanovsky, Las fotos, publicado en el 2020, en vínculo con su crónica «Que tengan buen viaje!», publicada en la revista argentina Anfibia en el 2018. La principal hipótesis parte de repensar los modos de producción artístico-cultural que esta hija de exiliados de una segunda generación ha desarrollado luego del retorno a la Argentina, cuando inició la democracia en 1983. Denomino «retratos de experiencia» a la mirada desde la conjunción entre la palabra y la imagen, en medio de trabajos con la memoria (Jelin 2012), que han permitido complejizar una forma escritural que da lugar a nuevas técnicas de desarchivo (Didi-Huberman 2017). Hago énfasis en una escritura que retoma las experiencias vividas en el pasado exiliar. Se demuestra un trabajo de documentación, con pruebas históricas, familiares y colectivas, del avance del terrorismo de Estado (en algunos relatos) hacia lo íntimo.
\end{abstract}

Palabras clave: desarchivo; experiencia; retratos; segunda generación; Ulanovsky.

\section{Portraits of experiences: ways of narrating life in Las fotos and "iQue tengan buen viaje!" by Inés Ulanovsky}

\section{Abstract}

I analyze Inés Ulanovsky's latest book, Las fotos (2020) in connection with her chronicle "¡Que tengan buen viaje!", published in the Argentinean cultural magazine Anfibia in 2018. The main hypothesis starts from rethinking the modes of artistic-cultural production that this daughter of exiles of a second generation has developed after the return to Argentina, when democracy

\footnotetext{
${ }_{1}^{1}$ Procedencia del artículo: Este artículo se inscribe en el proyecto de investigación actual, el cual está vinculado con las producciones artísticas de los hijos e hijas de exiliados y exiliadas durante la dictadura, sobre todo aquellos que se alojaron en México durante la década de los setenta cuando el terrorismo de Estado azotó a Argentina y a varios países de Latinoamérica
}

Esta obra está bajo una Licencia Creative Commons Atribución-NoComercial Compartirlgual 4.0 Internacional. 
began in 1983. I call "portraits of experience" to the view from the conjunction between the word and the image, in the midst of works with memory (Jelin 2012), which have allowed to make a scriptural form more complex to give rise to new archiving techniques (Didi-Huberman 2017). I emphasize a writing that takes up the past experiences lived in the exile. A documentation work is demonstrated with historical, family, and collective evidence on the advance of State terrorism (in some stories) towards the intimate.

Keywords: experience; second generation; pictures; Ulanovsky; unarchive.

Recibido: 15 de noviembre del 2020. Aprobado: 05 de febrero del 2021

Artículo de reflexión

https://doi.org/10.25100/poligramas.v0i53.11428

\begin{abstract}
¿Cómo citar este artículo en MLH? - How to quote this article in MLA?
Argañaraz, María Eugenia. "Retratos de experiencias: formas de narrar la vida en Las fotos y "iQue tengan buen viaje!» de Inés Ulanovsky" Poligramas 53 (2021): e.2111428 Web. Fecha de acceso (día, mes en mayúscula y abreviado, y año).
\end{abstract}

"somos argentinas y cuando se vayan los malos vamos a volver" (Inés Ulanovsky - Mariana Casullo, revista Anfibia, 2018)

"El no contar la historia sirve para perpetuar su tiranía"

(Laub 1992)

En este trabajo me interesa exponer formas diversas de mostrar y presentar las experiencias de vida, a través de lo que denomino «retratos de experiencias». De ahí la decisión de observar y analizar modos escriturales en la crónica escrita por Inés Ulanovsky "¡Que tengan buen viaje!", 
publicada en la revista cultural argentina Anfibia, en el 2018, y en su obra Las fotos, en el $2020^{2}$.

La familia de Inés Ulanovsky fue una de las tantas que residió en México. Carlos Ulanovsky, su padre, quien tuvo, junto a otros intelectuales, una participación importante en los Comités de Organización Nacional para con el Pueblo Argentino en México³ ${ }^{3}$ escribió en 1983 un libro de crónicas del exilio titulado Seamos felices mientras estamos aquí. Es uno de los libros que mejor sintetizó la experiencia desgarradora de miles de argentinos y argentinas. Esta obra se presenta como un documento entrañable, reconocible y universal, donde su autor describe a México como un mundo bien diferente a su aldea natal y lo consagra como su otro lugar en el mundo.

Las familias exiliadas construyeron en México un trabajo con la memoria, que ha incluido los lugares de lo afectivo a través de diversos registros artísticos. Resignificando dicha construcción de esta segunda generación de hijos e hijas del exilio, denomino "retratos de experiencias" a un modo diferente de narrar las vivencias, por parte de una generación que -desde el inicio del retorno- no ha dejado de contar y narrar lo acontecido, en vínculo estrecho con su infancia, y lo vivido una vez que pisaron suelo argentino luego del exilio. Me interesa analizar de qué manera esta segunda generación construye una memoria que irrumpe con la de sus padres también exiliados. En este sentido, uno de los puntos de partida es Los trabajos de la memoria de Elizabeth Jelin, ya que me permite visualizar que ubicar temporalmente a la memoria significa hacer referencia al "espacio de la experiencia» en el presente. Esto involucra al recuerdo de manera dinámica, sin olvidar que las experiencias incorporadas en el pasado pueden modificarse posteriormente (47).

\footnotetext{
${ }^{2}$ El interés por la escritura de Inés Ulanovsky se desprende de un proyecto mayor posdoctoral, donde indago las producciones artísticas-culturales de los hijos e hijas de exiliados/as de una segunda generación. Muchos de estos/as hijos/as estuvieron, junto a sus familias, por un período de tiempo considerable en México, producto del terrorismo de Estado, en medio de la última dictadura cívico-militar argentina. México no solo fue receptor de muchísimos latinoamericanos que se encontraban en una situación de vulnerabilidad extrema en sus países, sino que, además, cobijó a las y los exiliados/as desde el acompañamiento a través de organizaciones de militancia. ${ }^{3}$ Con democracia y con dictadura, el exilio argentino fue el único que tuvo dos "casas": la del Comité de Solidaridad para con el Pueblo Argentino (COSPA), y la del Comité Argentino de Solidaridad (CAS). Rodolfo Puiggrós y el exgobernador de Córdoba (Argentina) Ricardo Obregón Cano presidieron el COSPA. El escritor Noé Jitrik y el ex Ministro del Interior de Héctor José Cámpora (Presidente de la Nación Argentina entre mayo y julio de 1973), Esteban Righi, impulsaron el CAS. Ver en: https://www.nodal.am/2016/03/mexico-y-el-primer-exilio-politicoargentino-1974-76-por-jose-steinsleger/
} 
Teresa Basile, en su libro Infancias. La narrativa de Hijos, pone el foco en esta segunda generación, que diferencia a los padres de los hijos y que también padeció el terrorismo de Estado. Estos hijos e hijas han dado cuenta de diversas memorias y de una niñez vivida bajo una dictadura que Basile distingue dentro de series categóricas centrales, tales como: la infancia educada, la infancia clandestina, la infancia huérfana, la infancia apropiada y las infancias violentas. No se han abordado aquí las infancias exiliadas, y, por ello, la propuesta es observar la crónica de Ulanovsky «iQue tengan buen viaje!», sin dejar de lado el recuerdo de infancia de su autora. En este punto, Ulanovsky de modo historiográfico revisita los momentos previos de su regreso familiar a la Argentina en el vuelo 385 de Aerolíneas Argentinas, procedente de la Ciudad de México. Allí, muchos exiliados retornaban a su país natal. En el caso de Inés, el "retorno» fue para ella un nuevo exilio, porque cuando abandonó el país tenía unos pocos meses de vida; por ende, su infancia - hasta ese momento- había sido puramente mexicana. "iQue tengan buen viaje!» puede considerarse como una crónica que va detallando el paso a paso de ese retorno tan esperado por muchísimos argentinos/as que habían padecido el terrorismo de Estado. Esta crónica, de modo secuencial, narra las sensaciones de un momento crucial en el que muchas/os de estas hijas e hijos de esta segunda generación se presentan como argenmex ${ }^{4}$, puesto que no pueden dejar de considerarse como parte de las dos patrias.

Es indispensable hacer foco en lo que Basile menciona sobre la insistencia con la que los hijos se leen, miran y comparten sus producciones. Las preguntas versan acerca de ¿cuáles son las claves compartidas y los intereses comunes, qué problemas acarrea y cuáles son los alcances de los límites de la etiqueta "Literatura de Hijos/as"? (Basile 23). Desde estos interrogantes, Ulanovsky configura nuevos modos de narrar, llevando a cabo un trabajo con lo memorial, donde la matriz del universo familiar (como también Basile la estudia) caracteriza a

\footnotetext{
${ }^{4}$ En varios estudios sobre los argentinos y argentinas que estuvieron exiliados/as en México, críticos como Pablo Yankelevich, en Ráfagas de un exilio. Argentinos en México 1974-1983, y Jorge Luis Bernetti y Mempo Giardinelli, en México el exilio que hemos vivido. Memoria del exilio argentino en México durante la dictadura 1976-1983, han referido cómo los argentinos/as que por un largo tiempo residieron en México decidieron denominarse argenmex. Es necesario dar cuenta de que este término fue usado sobre todo por esta segunda generación de hijos e hijas. Un ejemplo oportuno es el documental de Violeta Burkart Noé Argenmex, exiliados hijos, de 2007 , en el cual se reflexiona sobre la construcción identitaria de la generación de hijos de exiliados políticos expulsados por la última dictadura cívico-militar argentina (1976-1983); es decir, aquellos hijos e hijas de padres argentinos que han nacido o crecido en México y que, al retornar, se denominaron a sí mismos como argenmex, por no poder dejar de lado hábitos y costumbres mexicanas, al igual que el espacio de pertenencia. Este hecho no es menor, dado que, posteriormente, muchos hijos e hijas, que son protagonistas testimoniales directos de este documental, se organizan y conforman el Colectivo de Hijos e Hijas del Exilio, en el 2006.
} 
esta segunda generación, para llegar a impregnar las producciones culturales propias, dado que los militares y luego los organismos de derechos humanos apelaron a "la familia» en sus discursos y estrategias políticas. Desde ahí se articularon dos intereses: la familia como política y la familia como afectividad, aunque están íntimamente relacionadas, entendiendo que la dictadura militar, al introducirse en la intimidad de los hogares, supo quebrar los límites entre lo público y lo privado (Basile, Infancias 30).

En este sentido, muchos hijos e hijas han reelaborado el concepto de archivo. DidiHuberman lo aborda en El archivo arde, puesto que de manera inevitable debe ser construido. Este se trabaja en articulación con otros montajes y, a su vez, con diversos archivos (7). El archivo se conforma probablemente como un acto de visibilización, de memoria recurrente y necesaria que busca varios retratos de experiencia para ser compartidos entre los miembros de una sociedad que ha sido víctima del horror.

Las obras trabajadas en esta instancia aluden a una hija de exiliados argentinos en México que escribe no solo desde su testimonio como observadora, sino también desde su experiencia como exiliada durante su infancia en México, para conformar posteriormente diversas crónicas en donde las fotografías también historizan y se visualizan como imágenes que arden de memoria (Didi-Huberman). De este modo, los "retratos de experiencia» son interpretados como formas de narrar la vida, no son solo imágenes que se plasman en un trabajo elaborativo y en la configuración de formas de narrar que distinguen entre pasado, presente y futuro, generando un lugar de posibilidades con respecto a ser un oyente ético y político (Jelin 49).

Inés Ulanovsky es parte de una segunda generación que ha podido transmitir y revisitar, haciendo uso de lo artístico, una situación de desarraigo de hijos/as, padres y madres. A través de una forma escritural, Ulanovsky decide presentar su historia y la historia de dos generaciones. "iQue tengan un buen viaje!» está diagramada de forma secuencial, con apartados subtitulados que en este análisis caracterizo como "retratos de experiencia» y que son los siguientes: irse, vivir, volver, despedirse, partir, despegar, aterrizar y llegar. Todos infinitivos y solo un verbo con pronombre enclítico que conceptualiza el encuentro con otros para fundirse no solo en el abrazo, sino también en el recuerdo de los años en México. Dice Inés Ulanovsky, en medio de estos «retratos de experiencia»: 
Yo sabía que había nacido en Argentina, pero no entendía demasiado qué quería decir. Argentina era un concepto difuso para mí. Era el dulce de leche, los alfajores Havanna que cada tanto aparecía, la bandera celeste y blanca -que durante bastante tiempo confundí con la uruguaya- mis abuelos y los militares. No mucho más (Que tenga párr. 8).

En lo narrado es significativa la mención de otros hijos e hijas que tomaron el mismo vuelo para regresar a la Argentina y que plasmaron en sus vidas el momento de la partida y del próximo retorno. Allí, estos exiliados/as posibilitaron los trabajos de la memoria, como lo aborda Elizabeth Jelin, quien plantea que el espacio de la memoria es un lugar de lucha política, no como lucha en contra del olvido, sino desde la acción de recordar para no repetir. Los trabajos de la memoria actúan como un dispositivo que permite incorporar experiencias del pasado para dar paso a procesos de significación y resignificación subjetivos, a través de los cuales los sujetos de la acción se mueven y orientan (o se desorientan y se pierden) (12).

Por ello, en la crónica de Ulanovsky se observa un nuevo proceso que varía en cuanto a lo que es el archivo como función del Estado moderno (de acuerdo con Derrida). Hay un trabajo de desarchivo (Didi-Huberman) como operación que incorpora o suma lo no registrado en el archivo oficial, en una intención incluyente y democrática. Si el archivo es la ley y su institución, la noción de desarchivar puede referirse a la desobediencia ante lo que se puede recordar y, por tanto, ante lo que se puede decir. Surge, en este sentido, la reconstrucción del recuerdo de una infancia exiliada, acompañada por otros niños y niñas en su misma situación. El trabajo de la memoria en este caso estaría dado desde el acopio de un archivo memorial y fotográfico personal que secuencia la experiencia individual y colectiva atravesada al momento del retorno. Por ello, cuando nos preguntamos ¿de qué hablamos cuando hablamos de memorias?, nos referimos a modos de recuerdos y olvidos en narrativas, silencios y gestos. Un juego de saberes con emociones, huecos, fracturas (Jelin 52), que deben ser albergados en una historización familiar, testimonial, que no dé lugar al olvido. Los "retratos de experiencia» son, principalmente, mecanismos que traen del pasado una memoria necesaria para poder transitar el presente y el futuro; para pensar desde allí lo social.

Gabriela Portantiero tiene grabado el momento en el que entró con las valijas en la mano después de pasar por migraciones: "Vi a mis abuelas y sentí el impulso de subirme de nuevo al avión. Sentí que lo que me esperaba era denso y pesado como el clima 
húmedo de ese día". Nicolás Gadano también se acuerda del calor, y de que su primo Nacho le advirtió que en Argentina la camisa se usaba adentro del pantalón. El señor de migraciones les hizo un "chiste" para nada gracioso a los hermanos Gadano. Les preguntó si en el estuche de la guitarra que traían había ametralladoras, porque en México eran "todos guerrilleros". Bienvenidos a la Argentina (Ulanovsky, Que tengan párr.30).

Al puntualizar la memoria, hay un trabajo de archivo como aval del porvenir, de aquello que no se cierra jamás, sino que se abre constantemente (Derrida), lo que permite revisitar cómo las memorias individuales se encuentran enmarcadas socialmente. Así, se centra la atención en los procesos de construcción de memoria colectiva en vínculo con nuevas formas de hacer archivo o desarchivo. Aquello que inevitablemente Didi-Huberman complejiza como "archivo en construcción».

Esta segunda generación ha dado testimonio y narrado lo que sus padres y ellos vivieron durante sus años de exilio en México (en este caso). Muchos hijos e hijas de exiliados/as han logrado reelaborar el trauma (tal como lo aborda Jelin) mediante trabajos exhaustivos con la memoria, los cuales se articulan aquí con momentos que son plasmados en retratos/cuadros de experiencia que acompañan posteriormente sus vivencias, el retorno del exilio y el transitar el presente, albergando las infancias exiliadas. Desde este lugar, el recuerdo implica un trabajo personal e individual, no se necesita solo de una «memoria» en la exploración de esas infancias, pues se requiere reconocer también esos riesgos de la memoria, sus «maleficios», como los ha llamado Basile. El explorar se transforma en un "hacer memoria» desde lo múltiple para no repetir, para dar lugar a formas de lecturas configuradas por, en el caso de Ulanovsky, una hija exiliada que decide narrar desde la conjunción del relato con la imagen, la fotografía. En «iQue tengan buen viaje!» se incorporan fotografías que no solo refieren a la infancia de Inés en México, sino, principalmente, fotografías que remiten al fin de esa infancia exiliada. Se visualizan los momentos en que la niña de seis años (Inés), junto a su hermana (Julieta), sus padres y algunas amigas como Mariana Casullo, se encuentran en el aeropuerto Benito Juárez de la Ciudad de México a punto de iniciar el camino del retorno.

La diferencia aludida con respecto a nuevas formas de narrar, que se observan como "retratos de experiencia», refieren cómo las memorias individuales se encuentran enmarcadas socialmente; por lo tanto, toda memoria se presenta como una reconstrucción, más que como un recuerdo. Los «retratos de experiencia» son operativos para una escritora como Ulanovsky, 
porque implican un trabajo con el archivo disruptivo (desarchivo) que afirma la existencia de una memoria colectiva y no de una única memoria. Surge un entretejido de memorias individuales, la de Inés Ulanovsky como testigo directa de una infancia exiliada, sumada a la de otras memorias individuales que se vinculan con grupos y organizaciones de derechos humanos que rememoran continuamente desde múltiples lugares.

Rememorar corresponde a una experiencia pasada, pero también a un acto del presente, a una necesidad, a la urgencia de mirar retratos que activan el presente para comunicar, de allí en adelante, aquello que no se debe olvidar, involucrando dos tipos de memorias: las memorias habituales y las narrativas (Jelin 62). Justamente, los "retratos de experiencia» se engloban dentro de memorias narrativas que permiten encontrar los sentidos del pasado y sus heridas. Actúan como construcciones sociales que son observadas continuamente y que, en el caso de esta segunda generación, dan lugar a una nueva literatura, con alcances en los que no es suficiente solo "el contar», dado que se necesita incluso «un mostrar», no como complemento de lo textual, ni como imágenes que "acompañan» testimonios. Hay mucho más que eso, es un trabajo múltiple que permite la conjunción de lo artístico desde diferentes aristas, como se observará en Las fotos

\section{Retratos híbridos}

Las fotos, del 2020, es el tercer libro de Inés Ulanovsky. Previamente, la autora escribió Fotos tuyas, en el 2006, y Algunas madres también se mueren, en el 2010. En su último libro, texto e imagen son también performáticos, como lo señala María Moreno ${ }^{5}$, toda vez que recrean memorias, lugares, modos de haber transitado un pasado plasmado en un momento fotográfico, así como un conjunto de relatos que explican otro tipo de memorias, las cuales son diferentes en relación con la crónica que la autora expone en la revista Anfibia. Las fotos muestra un claro interés con respecto a un trabajo de desarchivo que Ulanovsky lleva a cabo. Continúa indagando sobre la memoria que no remite solo a lo exiliar o al trauma del terrorismo de Estado, pues narra, además, una serie de historias que exceden lo privado, lo personal y apelan a lo público, a modos de memorias recopiladas en un trabajo mediante una nueva técnica de archivación. Hay un trascender para contar la vida desde otros espacios, para darle un lugar a la memoria

\footnotetext{
${ }^{5}$ En contratapa del libro Las fotos.
} 
que contempla una nueva técnica de hacer archivo, donde no se opta por una secuencia y no se expone desde lo privado, sino desde lo público. Ulanovsky trabaja en la conformación de un libro que reúne relatos, crónicas, en los cuales interesan múltiples memorias: familiares, sociales, históricas, literarias. Todas unidas mediante la fragmentación de lo diverso, pero también a través de fotografías diferentes que no explican la historia narrada porque se explican a sí mismas. No actúan como complementos de lo textual porque se trabaja sobre y con las memorias del pasado. Los «retratos de experiencias» a los que me referí en el apartado anterior se vinculan con actos diversos de rememorar la experiencia del pasado que la propia Ulanovsky activa en el presente, desarchivando. En este sentido, no hay una estructura para contar, ni mucho menos para mostrar; hay un deseo unido a una intención comunicativa que da lugar a retratos híbridos, capaces de abarcar diferentes contextos sociohistóricos.

Es necesario reconocer, además, que, en Las fotos, Ulanovsky advierte que las memorias se construyen y cobran sentido en cuadros sociales. La memoria funciona en esta instancia como una operación para dar un mayor sentido al pasado, en donde su autora se pregunta ¿a qué se refiere la experiencia? Quizás a las vivencias directas, inmediatas, subjetivamente captadas de la realidad (Jelin, Los trabajos 34).

Ulanovsky destaca lo histórico desde lo íntimo, lo familiar, que no siempre refleja el relato de lo dictatorial, apuesta a un recuerdo transversal que acapara a los años del terrorismo de Estado y que en Las fotos se genera a través de un proceso de desarchivo; es decir, el contar desde la experiencia y las experiencias, incluso desconocidas para la autora, que ha ido investigando/consignando, a lo largo de los años, por medio del uso de fotografías.

Ingresa el testimonio no solo desde el relato en sí, sino también desde cada foto que implica una multiplicidad de voces, de circulación de verdades y silencios, de cosas no dichas (Jelin). En cada fotografía conjugada con el texto hay transmisiones, herencias y aprendizajes que esta hija de exiliados lleva a cabo. Introduce lo autobiográfico, como, por ejemplo, el relato "La fotógrafa», en el cual hace mención directa de su madre fotógrafa, en 1974, y de su trabajo en la agencia Noticias Argentinas. Esta madre captura momentos del multitudinario sepelio de Juan Domingo Perón. En ese mismo año (1974), la madre, junto con su pequeña hija, se exilia a México y aparece aquí la voz directa de Ulanovsky, en clave autobiográfica, aludiendo a su madre: 
Creo que nunca se lo dije pero de todas sus versiones, la fotografía siempre fue mi preferida. Me gustaba ver eso que hacía cada vez que salía de trabajar: le ponía el cuello a la cámara, le cambiaba las pilas al flash, disparaba dos o tres fotos al aire y se colgaba su bolso verde, lleno de objetos extraños que me parecían fascinantes.

Ella fotografió mis primeros años de infancia con precisión técnica, responsabilidad documental y esa pulsión de registro que solo tienen las madres ("La fotógrafa” 55).

En Las fotos, asimismo, se mencionan otros retratos narrativos que refieren a la memoria del golpe de Estado de 1976, como, por ejemplo, el relato "La hija del tiburón», que describe a Mariana Eva Sala, hija de Néstor Carlos Sala, quien fue asesinado a sus 33 años en lo que se conoció como la Masacre de Margarita Belén, en Resistencia-Chaco (Argentina). Sala, desde 1969, integraba la Agrupación del Peronismo Universitario y formaba parte de FAR y Montoneros. Ulanovsky decide colocar, en medio de una multiplicidad de historias que son retratadas mediante las fotos y la narración, la imagen de Mariana Eva Sala de niña pequeña. Dicha fotografía le fue entregada a Mariana en 2011 -luego de 35 años- por Edgardo García, quien cuidó de ella durante el secuestro de sus padres.

Se pueden ubicar y contemplar estos trabajos escriturales como trabajos de la memoria, con uso del género testimonial (en ocasiones), un género con marcas particulares, inicialmente entendido como relato verosímil, con las marcas de la oralidad en las formas del realismo decimonónico (Nofal 837). En este sentido, se visualiza que en Las fotos prevalece un interés fundamental por historizar las memorias, desde lo personal y colectivo, desde la crónica y la imagen.

Rossana Nofal, en un arduo trabajo sobre los testimonios y sus configuraciones, según las cuales se organizan constelaciones del sentido sobre el pasado y sus disputas por las memorias, se detiene en el análisis de Williams (Williams a través de Nofal) con respecto a la escritura como forma de articulación y nueva formación que se extiende más allá de sus propios modos. Hay un espacio particular, desde lo escritural, que incluye lo testimonial como una historia susceptible de ser contada a través de lo artístico, para cuestionar no solo la forma, el modo, sino también resignificar lo historiográfico desde lo colectivo y lo familiar. La memoria, entonces, se produce a partir de lo que denomino "retratos de experiencia» en tanto hay sujetos que comparten una cultura, pero también con agentes sociales que intentan «materializar» estos sentidos del pasado en diversos productos culturales que son concebidos como vehículos de la memoria (Jelin 70). 
Desde allí, se pueden desprender diversas producciones artístico-culturales de estos hijos e hijas de una segunda generación. En este contexto, es inevitable preguntarse: ¿cómo se leen estos trabajos?, ¿para quién se testimonia? Unido a ello, Basile también señala, en Infancia. La narrativa de HIJOS, ¿cuáles son las claves compartidas y los intereses comunes?, ¿qué problemas acarrea esta fuerte pertenencia generacional?, ¿cuáles son los alcances y los límites de la etiqueta «iteratura de hijos»? (23).

En este sentido, la producción de Ulanovsky desarchiva como principio de consignación, es decir, de reunión (Derrida 11). Hay bloques de memorias que dan cuenta de lo historiográfico, del porvenir, demostrando que no se archiva de la misma manera. Desarchivo en el sentido de indagar en cada una de esas historias con sus fotos, en el interés por realizar un trabajo de campo, de entrevistas, de búsquedas que lleven a una pulsión de conservación que Derrida denomina la "pulsión del archivo». Se evita así la posibilidad del olvido, de la pérdida y se realiza un trabajo diferente, retratando experiencias a partir de la conjunción de historias e imágenes que son necesarias para configurar un desarchivo que no se cierra jamás, sino que se abre desde el porvenir (Derrida 37). Se ejemplifica el inicio de un proceso de revisión de fotos que Ulanovsky atesora desde hace tiempo. Así mismo, se especifica que todo comenzó (es decir, este trabajo de consignación) diez años después del atentado a la Asociación Mutual Israelita Argentina -AMIA-, en 1994, cuando la autora menciona que vivía enfrente de la mutual ${ }^{6}$ y que, por azar del destino, fotografió a su marido -fotógrafo- antes de conocerlo, desde la ventana de su casa, en uno de los aniversarios del atentado a la AMIA, mientras él capturaba otro momento a través de su cámara.

\footnotetext{
${ }^{6}$ Asociación Mutual Israelita Argentina (AMIA). Es una institución central de la comunidad Judía en Argentina. Fue creada en 1894 por un grupo de inmigrantes de origen judío. La AMIA está vinculada a muchos argentinos desde el inicio hacia el final de sus vidas. Los primeros inmigrantes judíos pudieron cumplir así en la nueva tierra que los albergó, con las leyes y costumbres milenarias que rigen la historia y las tradiciones de la comunidad. Una de las primeras acciones que llevó a cabo fue tener un cementerio comunitario. Con la llegada de los sucesivos contingentes migratorios, las actividades de la AMIA crecieron y se diversificaron. A partir de 1920, con el aumento de la población judía en Argentina y su progresiva integración a la sociedad, la institución se convirtió en el espacio de articulación y participación de los miembros del pueblo judío que se establecieron en Argentina. La pujanza de su desarrolló quedó reflejada cuando en 1945 abrió sus puertas en su histórica casa de Pasteur 633 en la Ciudad Autónoma de Buenos Aires. En 1994 para conmemorar el centenario de su creación, AMIA organizó una serie de festejos que fueron interrumpidos brutalmente el 18 de julio, cuando la sede fue blanco del terrorismo internacional. Desde entonces la institución no ha dejado de reclamar justicia. 85 personas fueron asesinadas en el peor ataque terrorista que sufrió la Argentina. La inauguración del nuevo edificio, emplazado en el mismo lugar que el anterior, se realizó el 26 de mayo de 1999, bajo el lema "Por la justicia y por la vida". El 13 de junio de 2006, AMIA inauguró su nueva sede ubicada en Uriburu 650, donde funciona el Centro Integral de Adultos Mayores (CIAM), el área de Servicio Social, Infancia, Discapacidad, Voluntariado, el Servicio de Empleo AMIA y el Programa Valor. Ver en: https://www.amia.org.ar/historia/
} 
Luego, al poco tiempo, surgió la idea en Ulanovsky de relacionar arte y testimonio, para contemplar otras aristas de la historia nacional argentina.

Didi-Huberman ha referido cómo el archivo debe ser abordado mediante cortes y montajes con otros archivos. Teniendo en cuenta dicho principio, dentro del universo familiar al cual se ha aludido en este artículo, las producciones culturales de esta hija, que ha vivido su infancia en el exilio, se conjugan con formas diversas de hacer archivo (desarchivar), a fin de establecer «retratos de experiencia» que requieren de una memoria narrativa indispensable, la cual articula los intereses de la familia desde lo político y lo afectivo. En este caso, lo afectivo y lo político íntimamente ligados, debido a que la dictadura militar supo quebrar límites, transgredir espacios e intimidarlos (Basile 30).

Dicho esto, la relevancia del sentido de la imagen con la que Didi-Huberman (2017) trabaja es recurrente en esta instancia para dar cuenta de cómo las memorias individuales se enmarcan socialmente, y, por ello, toda memoria es una reconstrucción, más que un recuerdo. Desde este punto, acudo a los «retratos de experiencia», los cuales requieren de una operación capaz de implicar un trabajo con las formas de un «hacer memoria», pero también de nuevos procedimientos de consignación donde el registro surge desde una irrupción que acapara diversos trabajos artísticos.

La imagen nunca es solo una incisión en el mundo de la visibilidad. Es aún más, una huella, una estela visual del tiempo (...), pero también de los tiempos complementarios -forzosamente anacrónicos, heterogéneos entre sí- que la imagen como arte de la memoria necesariamente agrega...Por eso arde la imagen. Arde de realidad... arde en la deconstrucción, en el fuego que casi carboniza, del cual sin embargo emergió y al cual ahora puede hacer imaginable. La imagen arde de memoria... una forma de dar expresión a su vocación de vida póstuma... (Didi Huberman 12).

Las fotos y la crónica «iQue tengan buen viaje!» se encargan de conjugar tiempos diferentes, pero a la vez propios de la segunda generación, y, en este sentido, se trata de un cruce de tiempos heterogéneos. En «iQue tengan un buen viaje!» las fotografías acompañan el relato autobiográfico de Ulanovsky. En su libro Las fotos hay un quehacer entre la imagen, la memoria y la casualidad, así como también entre la trama personal de padres, madres, hijos e hijas, maridos, esposas, que llega a alcanzar lo social, lo histórico y lo político del modo menos pensado. Se llega a observar 
en un relato como "Sudestada» las reminiscencias de un diario íntimo real de una de las mujeres involucradas en esa historia narrada.

Esta producción artística demuestra un trabajo minucioso de muchos años, principalmente, en archivos fotográficos, como lo es, por ejemplo, la labor desarrollada por Ulanovsky en El Archivo Nacional de la Memoria y el Archivo Biográfico de Abuelas de Plaza de Mayo, donde colaboró en el armado de cajas con documentos, fotos y entrevistas, destinadas a nietos y nietas que iban recuperando su identidad. De esta manera, esos nietos/as recuperados/as contaron con acceso de modo directo a archivos familiares. El oficio de Ulanovsky se desliza desde lo íntimo hacia un afuera y se complejiza. Leer su obra es como estar mirando una sucesión de álbumes fotográficos analógicos, a través de los cuales se interpela a los lectores y lectoras de modo constante y testimonial; con marcas particulares que impulsan lo narrativo y que generan interrogantes constantes, a modo de recortes que cada familia decide mostrar de sí misma, como si eligiesen qué foto compartir en medio de una reunión entre amigos. Sin olvidar que todo puede ser una foto, incluso la experiencia del momento.

Ulanovsky testimonia desde un presente que recopila su infancia exiliada, así como cada uno de sus trabajos vinculados con los procesos de archivos. Hay un trabajo no solo de recuerdo por parte de la autora como hija de exiliados, sino también un proceso de desglose en donde lo social tiene lugar en sus acciones, en su vida. Este ejercicio da cuenta de formas híbridas de testimoniar. Las fotografías, el uso de las crónicas nos permiten pensar en nuevos modos de abordajes e intervenciones en cuanto a un proceso de lectura que, en este caso refieren a cómo una hija del exilio muestra otras voces de aquellos que también sufrieron el trauma y que deben reconstruir, a veces desde el recuerdo y otras veces desde el recuerdo y una imagen. Surgen, de este modo, formas de testimoniar que acaparan diversos matices del arte, lo discursivo y un contexto sociocultural atravesado. En este sentido, Victoria Daona ha referido que los hijos e hijas de desaparecidos/as han utilizado diversas posibilidades de narración para enmarcar un nuevo género (37-55). Siguiendo esta línea, Inés Ulanovsky como hija de exiliados se posiciona dentro de lo que considero formas híbridas de dar testimonio a partir del recurso de la fotografía y el trabajo de consignación que indudablemente se conjuga con el recuerdo de una infancia exiliada. Si bien Las fotos no refiere a la infancia exiliada de la autora, hay matices, rasgos de otras infancias que se vinculan con lo dictatorial y que, en algunos casos, no se desprenden de lo traumático. 
El modo de enunciación desde el trabajo con la imagen da testimonio porque se observa el presente de la enunciación y el presente del enunciado. Esos modos de enunciación se unen a las experiencias vividas, y configuran procesos de transmisión memoriales no solo de las historias familiares sino, principalmente, de un contexto sociopolítico que necesita retratatarse y así configurar nuevos matices de la narrativa testimonial que ya se viene planteando en la crítica literaria, sin dejar de lado que no solo interesa la escucha, sino también la implicancia de las fotografías, incluso de aquellas imágenes de las no se es protagonista sino simplemente observador/a.

Sin lugar a dudas la matriz familiar recorre la infancia exiliada junto a los trabajos de archivos con fotos en las que son implicadas otras familias. Ulanovsky conforma una arquitectura narrativa que introduce nuevos modos de recepción y también de historización de una memoria colectiva para expandir otras memorias personales, íntimas que habilitan retratos de experiencia en los cuales no solo se mira una foto, se la llega a comprender en toda su complejidad.

\section{Referencias}

AMIA. https://www.amia.org.ar/historia/. 5 de Jun de 2021.

Basile, Teresa. Infancias. La narrativa argentina de Hijos. Villa María, Córdoba: Eduvim, 2019. Impreso.

Bernetti, Jorge y Mempo Giardinelli. México: El exilio que hemos vivido. Memoria del exilio argentino en México durante la dictadura 1976-1983. Provincia de Buenos Aires: Universidad Nacional de Quilmes, Editorial UNQ, 2003. Impreso.

Burkart Noé, Violeta y Analía Miller. "Argenmex, exiliados hijos". Documental. TFL. Ciencias de la Comunicación. UBA. YouTube. 2007. Web. 10 Nov. 2020 $<\underline{\text { https://youtu.be/zIET3bOgodA> }}$

Daona, Victoria , "Las voces de los/as hijos/as desaparecidos/as en Argentina: un género". El taco en la brea, n. ${ }^{\circ}$ 6, (2017): 37-55. DOl: <https://doi.org/10.14409/tb.v0i6.6963>. Digital. 7 Jun. 2021.

Derrida, Jacques. Mal de archivo. Una impresión freudiana. Madrid: Editorial Trotta, 1995. Impreso. 
Didi-Huberman, Georges. El archivo arde. Trad. Juan Antonio Ennis (para el uso de la Cátedra de Filología Hispánica de la Universidad Nacional de La Plata). 2017. Web. 10 Nov. $2020<$ https://filologiaunlp.files.wordpress.com/2012/05/el-archivo-arde1.pdf>.

Jelin, Elizabeth. Los trabajos de la memoria. Lima: Instituto de Estudios Peruanos - IEP, 2012. Impreso.

Jelin, Elizabeth. Pan y afectos. La transformación de las familias. Buenos Aires: Fondo de Cultura Económica, 2010. Impreso.

Laub, Dori. "Bearing witness or the vicissitudes of listening". En S. Felman y D. Laub, Testimony: Crises of witnessing in literature, psychoanalysis, and history. New York: Routledge, 1992. Impreso.

Nofal, Rossana. "Configuraciones metafóricas en la narrativa argentina sobre memorias de dictadura". KAMCHATKA. Dic. 6. 2015: 835-851. Digital. 7 Jun. 2021.

Steinsleger, José, (2016). "México y el primer exilio político argentino (1974-76)". Nodal (Noticias de América Latina y el Caribe). Marzo, 2016. Mar. 2021. https://www.nodal.am/2016/03/mexico-y-el-primer-exilio-politico-argentino-1974-76por-jose-steinsleger/

Ulanovsky, Inés. Las fotos. Buenos Aires: Paisanita Editora, 2020. Impreso.

Ulanovsky, Inés, (2018). "iQué tengan buen viaje!”. Anfibia. 23 ene. 2018. 8 Nov. 2020 $<$ http://revistaanfibia.com/cronica/que-tengan-buen-viaje/>.

Yankelevich, Pablo. Ráfagas de un exilio. Argentinos en México, 1974-1983. Buenos Aires: Fondo de Cultura Económica de Argentina, 2010. Impreso. 